\title{
Upper Mantle Structure Beneath the Japan Trench and Tohoku Arc Viewed from Mantle Bouguer Anomalies
}

\author{
By Hiromi Fujimoto*) and Maki Iто**) \\ (Communicated by Yoshibumi Tomoda, M. J. A., April 12, 1996)
}

\begin{abstract}
Mantle Bouguer gravity anomaly gives density anomaly in the upper mantle. We compiled the mantle Bouguer anomaly in the Japan Trench and Arc using data of crustal structure given from explosion seismology. A profile of the gravity anomalies across the subduction zone shows a regional positive anomaly over the island arc. The profile also shows local low-density anomalies beneath the central part of the island arc and near the trench axis. A relatively positive anomaly of about 70 mgals still exists over the island arc after removing the effect of the subducting slab. We suspect missing of the low-density layers on the surface of the slab can explain the result. The low-density zone beneath the central part of the island arc relates to the zone of volcanic activity expected from petrological studies. Another low density zone relates to accretion of sediment near the trench axis.
\end{abstract}

Key words: Mantle Bouguer anomaly; Japan Trench and Arc; upper mantle structure; arc volcanism; seamount.

Introduction. Major sources of gravity anomalies near the surface of the Earth are the surface topography, crustal structure and density anomalies in the upper mantle. By removing the effect of a surface structure, we can see the deeper structure. For example, Bouguer anomaly gives the structure in the crust and upper mantle, because the effect of the topography is removed. In the same way, mantle Bouguer anomaly shows density structure in the upper mantle below the Moho, because the effect of crustal structure above the Moho is removed.

Explosion seismology gives velocity structure. An empirical relationship between velocity and density ${ }^{1)}$ gives density structure. The density structure gives mantle Bouguer anomaly, which is equivalent to the "residual gravity anomaly (R.G.A.)" introduced by Yoshii ${ }^{2)}$ for the studies of the upper mantle structure.

Mantle Bouguer anomaly in the Japan Trench and Arc. In one dimensional case, mantle Bouguer anomaly (MBA) is expressed by

$$
\mathrm{MBA}=\text { F.A. }+2 \pi \mathrm{k}^{2} \sum_{\mathrm{i}}\left(\rho_{\mathrm{m}}-\rho_{\mathrm{i}}\right) \mathrm{H}_{\mathrm{i}},
$$

*) Ocean Research Institute, University of Tokyo, 1-15-1 Minamidai, Nakanoku, Tokyo 164, Japan.

**) Technical Department, Metal Mining Agency of Japan, 1-24-14 Toranomon, Minatoku, Tokyo 105, Japan. where,

$\rho_{\mathrm{m}}$ : density of the upper mantle assumed as 3.3 $\mathrm{gr} / \mathrm{cm}^{3}$ corresponding to $\mathrm{p}$ wave velocity of $8.1 \mathrm{~km}$

$\rho_{\mathrm{i}}$ : density of the i'th layer of the crust,

$\mathrm{H}_{\mathrm{i}}$ : thickness of the i'th layer,

$\mathrm{k}^{2}$ : universal constant of gravitation, and

F.A. : free air gravity anomaly.

In one-dimensional case, calculation of MBA assumes that the layers are approximated by infinite plate of constant thickness. This approximation corresponds to simple Bouguer anomaly. In other words the approximation means that we consider only the structure just beneath the observation point. In the present paper, we calculated the MBA based on twodimensional structure. Each layer of the crust is approximated by a polygon and the gravity effect is calculated by integrating the effect of all these polygons.

There are about sixteen profiles of explosion seismology in and around Japan, where velocity structure above the Moho surface is observed. Fig. 1a shows the location of these profiles (B1-5, A1-2, S1-7, Profile Tohoku and Profile Philippine Sea). Mantle Bouguer gravity anomaly is calculated for these profiles. Land gravity data are Bouguer anomalies 


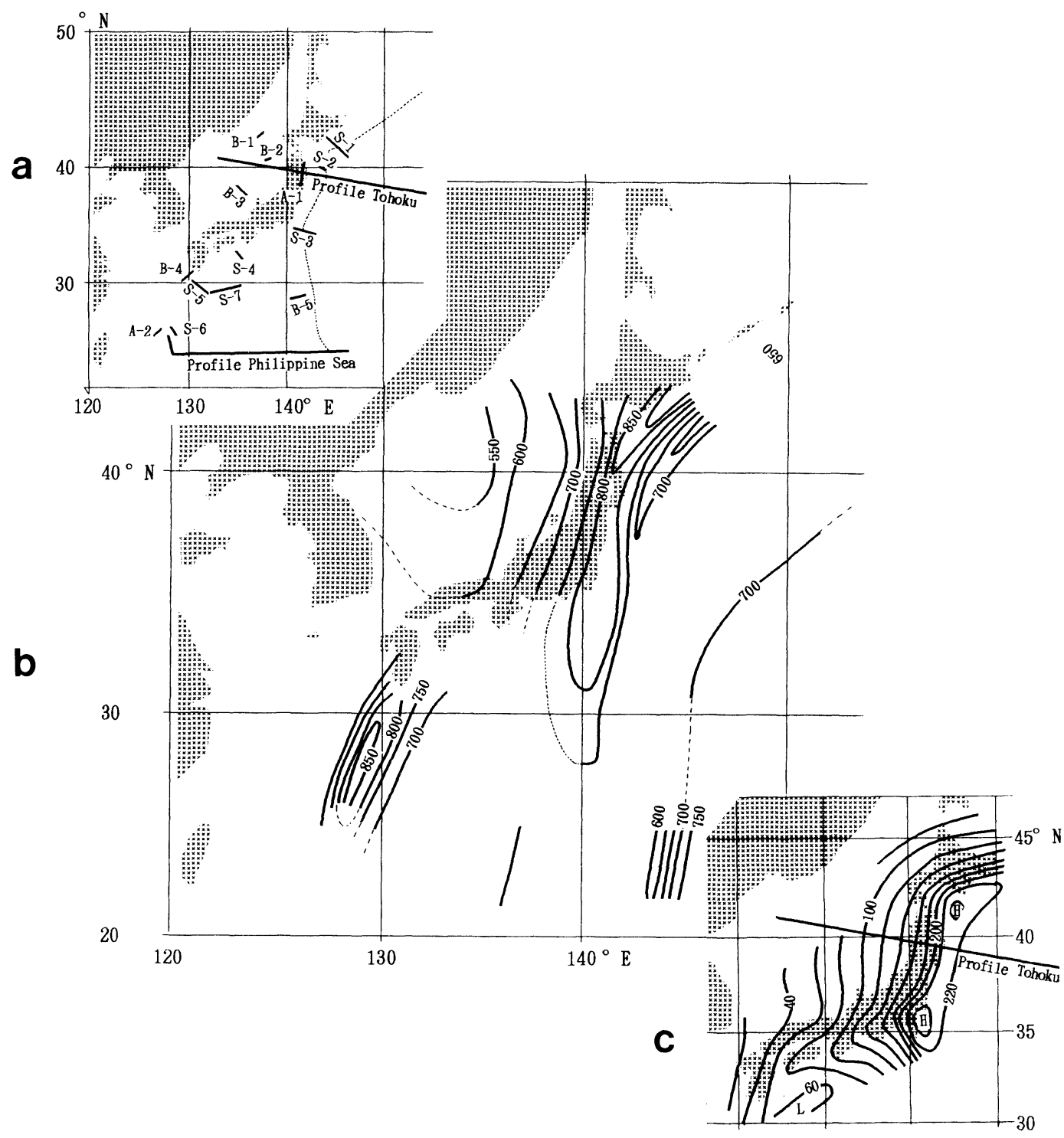

Fig. 1. a, Location of the profiles of explosion seismology. Dotted line: Trench axis, A: Profile in the island arc, B: Profile in the basin, S: Profiles in the subduction zone. b, Mantle Bouguer anomaly in and around Japan. Unit: mgal. c, Effect of gravity due to the slab. ${ }^{3)}$ Unit: mgal.

compiled by Kono and Furuse ${ }^{3)}$ corrected for topography. Data at sea are free air anomalies and topography compiled by Tomoda and Fujimoto. ${ }^{4)}$

Fig. $1 \mathrm{~b}$ shows a map of the mantle Bouguer anomaly in and around Japan including marginal sea, subduction zones and the island arcs. The map shows three characteristics. 1) Positive mantle Bouguer anomalies exist over the island ares along the coast of Kuril to north west of Japan, and along the Ryukyu arc. 2) Anomaly in the Japan Sea is smaller than that of the Philippine Sea basin, though both areas belong to the marginal basin. 3) Local negative anomaly exists over the fose-arc of the Tohoku district.

A map showing effect of gravity due to subducting slabs around Japan is also compiled by Kono and Furuse. ${ }^{3)}$ They assumed the thickness of the Pacific plate to be $90 \mathrm{~km}$, and that of the Philippine Sea plate to be $30 \mathrm{~km}$. They also assumed density contrast of the slab to be $0.065 \mathrm{gr} / \mathrm{cm}^{3}$. Fig. 1c shows their results. Though there is quantitative difference, the general feature of the mantle Bouguer anomaly looks like the map showing the gravity effect of the slab.

Detailed studies along the Profile Tohoku. To interpret the origin of the mantle Bouguer anomaly, 


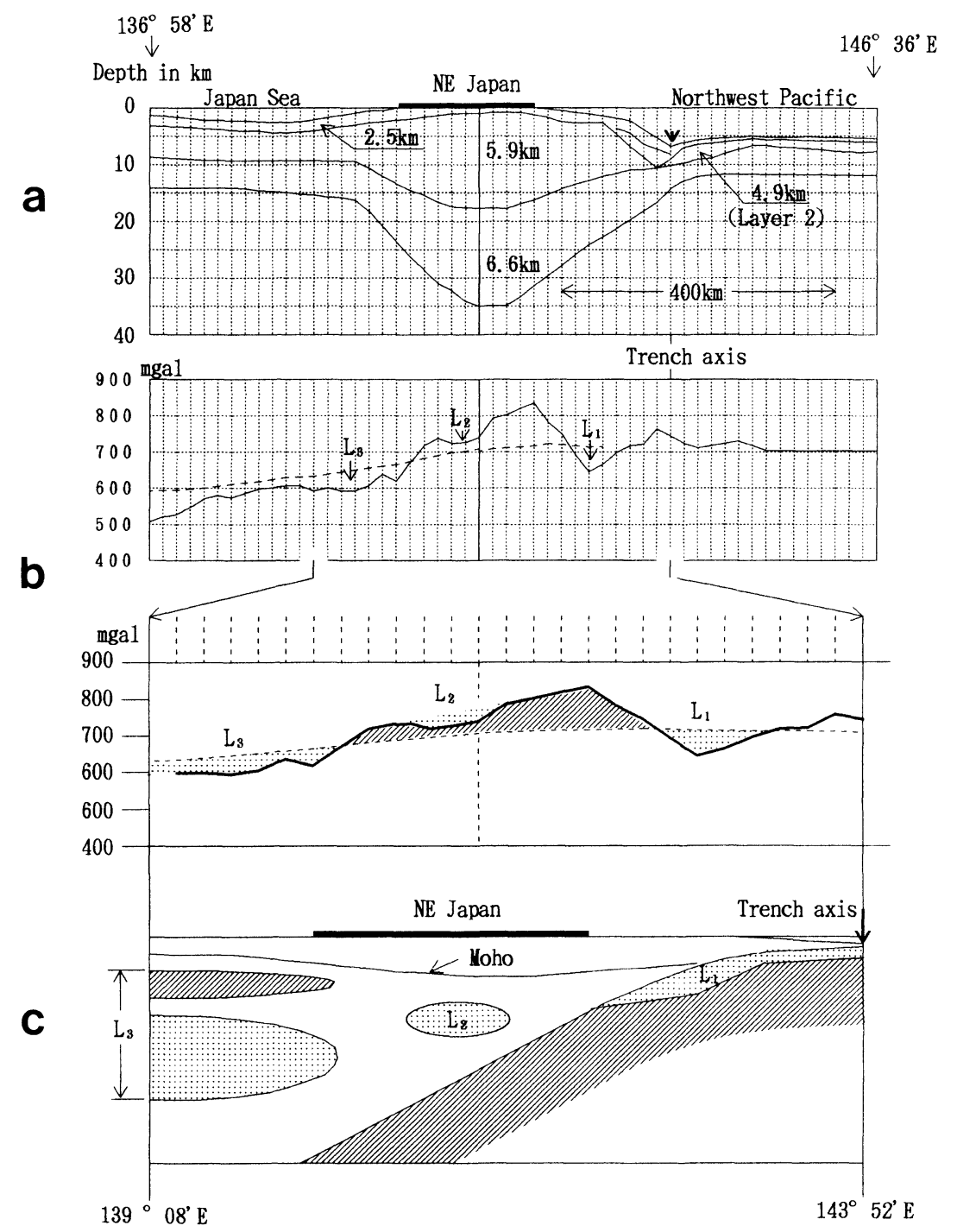

Fig. 2. a, Velocity structure along the profile Tohoku. b, Mantle Bouguer anomaly in the Profile Tohoku. Dotted line shows the effect of the slab. c, Schematic model to explain the Mantle Bouguer anomaly in the Profile Tohoku.

Profile Tohoku was compiled. The crustal section is shown in Fig. 2a. Most of the seismic profiles east of the are are in the N-S direction parallel to the Japan trench. These seismic experiments ${ }^{5)-9)}$ give velocity structure on the east side of the profile. The structure in the Japan Sea is the same as the previous interpretations. ${ }^{10)}$ We made a minor revision in the shallow crustal structure near the coast of the Japan Sea (K. Suyehiro, personal communication).

The gravity effect of the crustal structure was computed assuming a two-dimensional structure perpendicular to the profile. The density structures at the end of the profile were extending outward by $500 \mathrm{~km}$.
Results are shown in Fig. 2b. Anomalies are largest over the island arc and decrease toward the Japan Sea similar to the trends shown in Fig. 1b. A dotted line shows the effect of the slab along the compiled section read from the map shown in Fig. 1c. We fit the line so that the absolute value in the Western Pacific on the right-hand side of the profile match the observed mantle Bouguer anomalies. From Fig. 2b we see that even when the theoretical effect of the slab is removed, the features mentioned above still remain; mantle Bouguer anomalies are higher over the island are and lower in the Japan Sea than in the western Pacific. 
The primary difference between upper mantle structures in the Japan Sea and in the western Pacific is due to the difference in lithospheric thickness corresponding to the sea-floor ages, as discussed by Yoshii. ${ }^{2)}$ A present problem is how we explain large positive anomaly beneath the island arc of Japan that is difficult to explain by difference of age.

Regional high-density anomaly beneath the island arc and local low-density anomaly at the forearc. One possible process for a high-density structure beneath the island arc is that there is a thickening of the subducting slab associated with magma generation. The subducting lithosphere thickens as it releases latent heat and the generation of the basalt magma beneath the island arc may accelerate this process.

However, the authors suspect that missing of the sedimentary layer on the slab is responsible for the positive mantle Bouguer anomaly beneath the island arc. In calculating mantle Bouguer anomaly in the northwest Pacific region, structure covered with sediment was considered, but the existence of the low density layer such as sedimentary layer was neglected in calculating the effect of the slab. In other words, it is suspected that the positive anomaly can be explained, if the slab subducts to a certain depth with low density sediment on it. However, a sedimentary layer of $1 \mathrm{~km}$ thickness with density of $2.0 \mathrm{gr} / \mathrm{cm}^{3}$ can explain only half of the effect. It seems necessary to remove another layer of thickness of $1 \mathrm{~km}$ having velocity of about $5 \mathrm{~km} / \mathrm{s}$ (Layer 2 ) to explain the whole positive anomaly.

We can consider two models. 1) Sedimentary layers and the Layer 2 are removed by subduction process and are accumulated on the continental crust by accretion process. 2) Sedimentary layers and the layer 2 subduct with the slab, but their density becomes the same as that of the crust of $6 \mathrm{~km} / \mathrm{s}$ layer due to compaction. Fig. 2c schematically shows a model of the missing low density layer on the subducting slab. Though it seems difficult to select the better one at the present stage, we think the second model is reasonable, because material of too much volume must accumulate by an accretion process in the first model.

The gravity profile shows local minimum at the fore-arc. The local negative anomaly L1 in the fore-arc region has not been fully examined; it may be due to complicated crustal structure and sub-Moho lowdensity structure. ${ }^{11)}$ However, we suppose that an accumulated low density material such as sediments is the origin of the anomaly. The bulk of the low density material may stay near the trench axis until the density of its bottom becomes high by compression due to the weight above it.

Local low-density anomaly $L 2$ and regional lowdensity anomaly L3 (Fig. 2b) (relation with results of seismic tomography). Two minimums in the gravity anomalies (L2 and L3) of about $50 \mathrm{mgal}$ correspond to the low-velocity zones. We estimated the gravity effect of the low-velocity zones on the local gravity anomalies. A standard velocity profile was estimated from the Preliminary Reference Earth Model $(\mathrm{PREM})^{12)}$ and the velocity anomalies given by seismic tomography ${ }^{13)}$ were assumed to be deviations from the standard.

A low-velocity zone, with velocities $2 \%$ lower than the PREM model, continues to a depth of $65 \mathrm{~km}$ beneath the volcanic front. Mantle Bouguer anomaly estimated from the velocity anomaly is about $-66 \mathrm{mgal}$. This value is roughly equal to L2 shown in Fig. 2b. An extensive low-velocity zone exists in the Japan Sea from seismic tomography near Japan. ${ }^{13), 14)}$ A low-velocity zone ranges in the depth from $65 \mathrm{~km}$ to $140 \mathrm{~km}$ beneath the coast of the Japan Sea. Its gravity effect is about $-180 \mathrm{mgal}$. There is also a high-velocity zone in this area in the depth range 25 to $50 \mathrm{~km}$, which gives a positive gravity anomaly of +139 mgal. Total effect on the mantle Bouguer anomalies is $-40 \mathrm{mgal}$. This value also agrees with the local gravity minimum L3 in Fig. 2b.

These results show that the local minimums of the mantle Bouguer anomalies L2 and L3 are quantitatively explained by low-velocity structure obtained by seismic tomography. Fig. 2c schematically shows a model to explain the mantle Bouguer anomaly.

Summary. We found two important anomalies: 1) High-density anomaly beneath the island arc and 2) local low-density anomaly beneath the volcanic front. High-density anomaly is interpreted as the result of missing of sedimentary and second layers: gravity effects of these two layers disappear at a certain depth. Peak of the positive anomaly appears near the Pacific coast of the island arc and the depth of the slab there gives approximate depth of the missing of low-density layers. The depth is about 40 to $50 \mathrm{~km}$. Though we need further studies, we suppose that compaction is possible origin, and increase in density results in that the layers can subduct with the slab. The decrease of volume also makes a space to sink the body of the seamount and results in a break down of it such as Kashima seamount at the axis of the Japan 
trench.

The model can explain a local negative anomaly land side of the trench. Because, as shown from numerical simulation, low-density material on the subducting slab cannot easily sink with the slab, and is accumulated near the trench axis. We think that it can subduct when its density becomes the same as that of the crust there.

As for local low gravity anomaly beneath the Island arc, we found good correction with the results of seismic tomography. It has been found that negative free-air gravity anomalies are observed surrounding many seamounts in the western Pacific. Analyses of the density structure beneath the seamounts have shown that the negative gravity anomalies are not explained by crustal structure, but by low-density structure beneath the Moho. ${ }^{4), 15)}$ Thus, both the island arc and the seamounts have low-density structures of magmatic origin in common. The difference lies in the magma supply rate and the duration of the magmatic activity. ${ }^{15)}$ A seamount is considered to be formed when the underlying lithosphere is above a hot spot. The magma supply rate from a hot spot is much larger than the are volcanism. As the lithosphere moves at a speed of tens of millimeters per year, a seamount is formed from a large supply of magma within a short time on the geological time-scale. On the other hand, the rate of magma generation from the subducting slab is small, and the position of volcanism is fixed because magma generation is a pressure-dependent process. Consequently, magmatic activity beneath the island arc continues at the same places for a long time, with relatively small amount of magma supply. Given that a certain amount of time is required to generate the crust, it is well understood that the island arc has a thick crust while a seamount generally has a standard oceanic crust and low-density materials beneath the lithosphere. This interpretation is in agreement with the analyses that rises with thick crust were formed when hot spots were beneath ridge crests; magma is supplied to the rise for long time in such cases.

Acknowledgements. The authors are grateful to Kiyoshi Suyehiro for his help in compiling the crustal velocity section across the Japan Trench and Tohoku Arc.

\section{References}

1) Ludwig, W. J., Nafe, J. E., and Drake, C. L. (1970) In The Sea (ed. Maxwell, A. E.). John Wiley and Sons, New York, vol. 4, Part I, pp. 53-84.

2) Yoshii, Y. (1973) J. Phys. Earth 21, 313-328.

3) Kono, Y., and Furuse, N. (1989) Gravity Anomaly Map, Univ. Tokyo Press.

4) Tomoda, Y., and Fujimoto, H. (1982) Bull. Ocean Res. Inst., Univ. Tokyo, 14, separate foldout package.

5) Asano, S., Okada, H., Yoshii, T., Yamamoto, K., Hasegawa, T., Ito, K., Suziki, S., Ikami, A., and Hamada, K. (1979) J. Phy. Earth 27, 1-13.

6) Ludwig, W. J., Ewing, J. I., Ewing, M., Murauchi, S., Den, N., Asano, S., Hotta, H. Hayakawa, M., Asanuma, T., Ichikawa, K., and Noguchi, I. (1966) J. Geophy. Res. 71, 2121-2137

7) Okada, H., Asano, S., Yoshii, T., Ikami, A., Suzuki, S., Hasegawa, T., Yamamoto, K., Ito, K., and Hamada, K. (1979) J. Phys. Earth 27, 15-32.

8) Houtz, R., Windisch, C., and Murauchi, S. (1980) J. Geophys. Res. 85, 267-274.

9) Suyehiro, K., Kaiho, Y., Nishizawa, A., Kanazawa, T., and Shimamura, H. (1990) Tohoku Geophys. J., Sci. Rep. Tohoku Univ., ser. 5, 33, 281-305.

10) Shinohara, M., and Suyehiro, K. (1992) Earth Monthly 14, $341-347$

11) Tatsumi, Y. (1989) J. Geophy. Res. 94, 4697-4707.

12) Dziewonski, A. M. and Anderson, D. L. (1984) Phys. Earth Planet. Inter. 25, 297-356.

13) Hasegawa, A., Zhao, D., Hori, S., Yamamoto, A., and Horiuchi, S. (1991) Nature 352, 683-689.

14) Fukao, Y., and Obayashi, M. (1992) J. Geophys. Res. 97, $4809-4822$.

15) Tomoda, Y., and Fujimoto, H. (1996) Proc. Japan Acad. 72B, 39-43. 